(C) 2022, The Authors. Published by Elsevier Inc. and Fass Inc. on behalf of the American Dairy Science Association ${ }^{\circledR}$. This is an open access article under the CC BY license (http://creativecommons.org/licenses/by/4.0/).

\title{
Development of ruminating behavior in Holstein calves between birth and 30 days of age
}

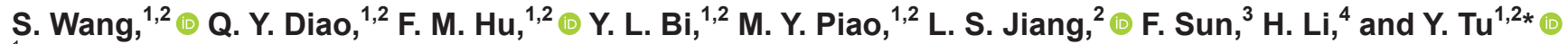 \\ ${ }^{1}$ Key Laboratory of Feed Biotechnology of the Ministry of Agriculture, Institute of Feed Research of Chinese Academy of Agricultural Sciences, \\ Beijing 100081, China \\ ${ }^{2}$ Beijing Key Laboratory for Dairy Cow Nutrition, Beijing University of Agriculture, Beijing 102206, China \\ ${ }^{3}$ Institution of Animal Husbandry Research, Heilongjiang Academy of Agricultural Sciences, Harbin 150086, China \\ ${ }^{4}$ JiuXing Dairy Farm, Beijing 101500, China
}

\begin{abstract}
Ruminating behavior accompanies the development of the rumen and the intake of solid feed in calves. However, few studies have reported on the emergence and development of rumination. In this study, we observed ruminating behavior changes of 56 Holstein calves (body weight at birth $=40.1 \pm 3.96 \mathrm{~kg}$; mean \pm standard deviation) from birth to $30 \mathrm{~d}$ of age under the feeding management of suckling calves that were only fed pelleted concentrate feed and milk. All calves were housed in individual pens equipped with infrared cameras. We explored feed intake within $30 \mathrm{~d}$ of age, body weight on $61 \mathrm{~d}$ of age, and other apparent indicators, including the age of first eating the bedding, duration of non-nutritive oral behavior at 25 and 30 $\mathrm{d}$ of age, total starter feed intake within $30 \mathrm{~d}$ of age, average daily starter feed intake within $30 \mathrm{~d}$ of age, and duration of ruminating behavior at 25 and $30 \mathrm{~d}$ of age for all calves, to further explore the effects of the age of first ruminating behavior (AFR). The AFR fitted the normal distribution and ranged from 15 to $20 \mathrm{~d}$ of age for $50 \%$ of the experimental population. The AFR was positively correlated with the age of first eating the bedding and duration of non-nutritive oral behavior at $30 \mathrm{~d}$ of age. Total starter feed intake within $30 \mathrm{~d}$ of age, average daily starter feed intake within $30 \mathrm{~d}$ of age, duration of ruminating behavior at 25 and $30 \mathrm{~d}$ of age, and duration of eating the bedding at 25 and $30 \mathrm{~d}$ of age were negatively correlated with AFR. Overall, to the best of our knowledge, this is the first study that has analyzed the correlation between AFR and other indicators. We found that earlier AFR was associated with shorter duration of non-nutritive oral behavior,
\end{abstract}

Received March 4, 2021.

Accepted August 16, 2021.

*Corresponding author: tuyan@caas.cn longer durations of rumination and eating the bedding, and higher feed intake by $30 \mathrm{~d}$ of age.

Key words: ruminating behavior, first rumination, performance, behavior of calves

\section{INTRODUCTION}

Ruminating behavior, a behavior that distinguishes ruminants from monogastric animals, is a physiological process that promotes the further breakdown and decomposition of herbivorous food and stimulates digestion (Heinrichs and Lesmeister, 2005). Furthermore, ruminating behavior can stimulate saliva production to maintain a healthy ruminal environment (Khan et al., 2016).

It is well known that the occurrence and development of ruminating behaviors depend on the ruminant anterior stomach (rumen and reticulum; Church, 1988). Newborn ruminants are usually considered monogastric due to the absence of rumination; however, they begin to ruminate a few weeks after birth as gastric functions gradually develop (Swanson and Harris, 1958; Baldwin et al., 2004; Porter et al., 2007). Once rumination begins, the rumination duration in calves keeps increasing rapidly with age (Swanson and Harris, 1958; Liu et al., 2019). Swanson and Harris (1958) found that the rumination duration could reach 185 and $297 \mathrm{~min} / \mathrm{d}$ at 23 and $65 \mathrm{~d}$ of age, respectively, and a high correlation $(\mathrm{r}=\sim 0.7)$ between rumination duration and intake of solid feed. Similarly, Liu et al. (2019) reported that rumination duration in calves increased significantly 1 wk after weaning. Furthermore, some studies have reported that calves fed on different types of solid feed exhibit different rumination durations at the same age (Swanson and Harris, 1958; Castells et al., 2012; Montoro et al., 2013). These results indicate that providing solid feed to young calves can promote the development of ruminating behavior.

The first occurrence of ruminating behavior precedes or coincides with intake of solid feed (Swanson 
and Harris, 1958). Thus, the occurrence of ruminating behavior in calves may also serve as a key marker for the development of the rumen. However, some studies have reported different results about the age of first rumination (AFR) in calves. Swanson and Harris (1958) found that dairy calves fed on coarse-chopped alfalfagrass-mixed hay exhibited first ruminating behavior during their second week of life. Porter et al. (2007) showed that the first ruminating behavior in calves that were not fed forage occurred at 4 wk of life. Ghassemi Nejad et al. (2012) found that initial rumination in calves fed only pelleted concentrate feed occurred at about $3 \mathrm{wk}$ of life, and no significant difference appeared in calves fed different diameters of pelleted feed; however, another study showed that calves fed only pelleted concentrate feed began to ruminate at $6 \mathrm{wk}$ of life (Khan et al., 2016). However, we found that these studies (Swanson and Harris, 1958; Porter et al., 2007; Ghassemi Nejad et al., 2012; Khan et al., 2016) did not use large sample sizes, uniform feeding management, the same behavioral evaluation criteria, and continuous behavioral observation methods to accurately evaluate first rumination in calves. In addition, a smooth transition to solid feed intake during the suckling period accompanied by sufficient rumination promotes higher starter intake and weight gain after weaning in calves (Khan et al., 2011a). However, it has not been reported whether the AFR in calves is correlated with feed intake, body weight, and other behavioral indicators such as rumination, standing behavior, and non-nutritional oral behavior during the suckling period.

Therefore, in this study, we observed the behavioral changes, especially rumination, in 56 Holstein calves from birth to $30 \mathrm{~d}$ of age under feeding management for suckling calves that fed only pelleted concentrate feed and milk, to provide new insights for optimizing calf feeding and management practices. In addition, we measured the feed intake, body weight, and behavioral indicators of all calves to further explore the effects of AFR behavior. We hypothesized that initial rumination of calves would correlate with the apparent indicators, including feed intake, body weight, ruminating behavior, and non-nutritional oral behavior, during the sucking period.

\section{MATERIALS AND METHODS}

Experimental procedures were approved by the Animal Ethics Committee of the Chinese Academy of Agricultural Sciences (AEC-CAAS-20190508; Beijing), and animal welfare and handling procedures were strictly followed throughout the experiment.

\section{Study Area}

This experiment was carried out at the Jiu Xing Dairy Farm, Beijing, China $\left(40^{\circ} 21^{\prime} 19.7^{\prime \prime} \mathrm{N}, 116^{\circ} 45^{\prime} 53.3^{\prime \prime}\right.$ $\mathrm{E} ; 49-74 \mathrm{~m}$ elevation). The farm is situated on flat land and experiences 4 distinct seasons.

\section{Preliminary Experiment}

A pre-experiment was conducted to determine locations for infrared camera installation, definitions for observed behaviors, and description of first rumination in the formal experiment. First, we observed the behavior of 4 calves of $25 \mathrm{~d}$ of age, referring to the behavioral criteria reported by Castells et al. (2012), Horvath and Miller-Cushon (2019), and Kargar and Kanani (2019), and refined behavioral definitions for use in the formal experiment (Table 1). Interestingly, we counted the number of time intervals that occurred within $5 \mathrm{~min}$ between 2 times of eating the bedding in the calves, and the actual distribution was as follows: 53 times in $<1$ min; 61 times in 1 to $2 \mathrm{~min}$; 16 times in 2 to $3 \mathrm{~min} ; 29$ times in 3 to $5 \mathrm{~min}$. Based on these results, the interval of eating the bedding behavior was set to $2 \mathrm{~min}$. If the calf resumed eating the bedding $\mathrm{N}$ times with no pauses longer than $2 \mathrm{~min}$, the duration of this behavior was calculated as follows:

Duration of 1 bout of eating the bedding $(\min )=$ duration of eating the bedding in $(\mathrm{N}+1)$ times $(\mathrm{min})$ + duration of the interval in $\mathrm{N}$ times (min).

Similarly, we counted the number of time intervals that occurred within 5 min between 2 times of rumination in the calves, and the actual distribution was as follows: 47 times in $<1 \mathrm{~min}$; 19 times in 1 to $2 \mathrm{~min}$; 31 times in 2 to $5 \mathrm{~min}$. Based on these results, the interval of ruminating behavior was set to $1 \mathrm{~min}$. In addition, referring to the results about bouts of pen-directed sucking and self-grooming by Horvath and Miller-Cushon (2019), the interval of non-nutritional oral behavior (NNOB) was set to $1 \mathrm{~min}$. If the calf resumed ruminating behavior or NNOB $\mathrm{N}$ times with no pauses longer than 1 min, the duration of 1 bout of ruminating behavior or NNOB was calculated as follows:

Duration of 1 bout of ruminating behavior or NNOB $(\min )=$ duration of ruminating behavior in $(\mathrm{N}+1)$ times $(\mathrm{min})+$ duration of the interval in $\mathrm{N}$ times $(\mathrm{min})$. 


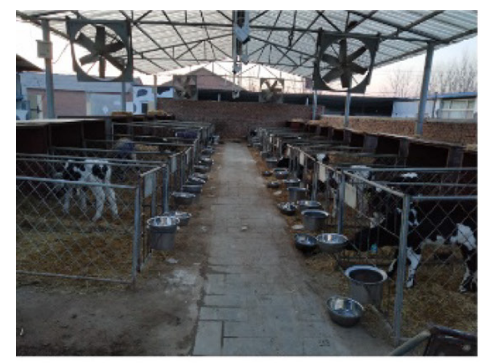

a

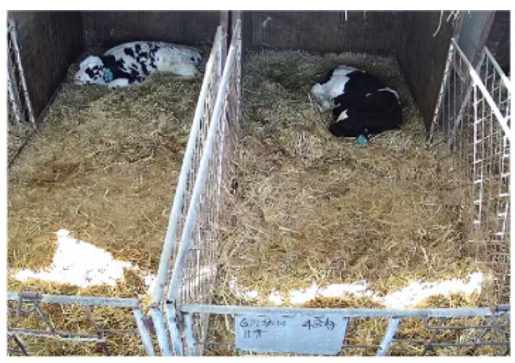

b

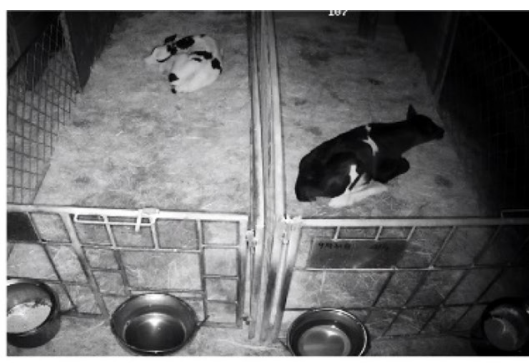

c

Figure 1. Installation overview and example of the camera's perspective. (a) Overview of the experimental environment; (b) example camera photo during daytime; and (c) example camera photo during nighttime.

To ensure the accuracy of behavioral data, effective ruminating behavior and eating of bedding must be longer than $10 \mathrm{~s}$, because we often found that some of the calves evinced brief (5-6 s) grinding behavior (grinding their teeth to produce a sound the same as human teeth grinding), and they licked the bedding and showed brief jaw movements (2-3 s) during routine inspections. Meanwhile, the cameras (50 Hz: 25 frames per second; Hikvision Digital Technology Co. Ltd.) were installed at a height of $2 \mathrm{~m}$ in front of the pens, and each camera recorded the behavior of 2 calves. Detailed installation locations and pictures of the cameras are shown in Figure 1. Because a description of first calf ruminating behavior was not found in any pervious article, three 3 -d-old and three 15-d-old calves that had not exhibited rumination were monitored continuously for $20 \mathrm{~d}$, and all video records were stored in 1 hard disk (Seagate, ST6000VX0023; 6 T, 7,200 RPM, 256MB cache). Next, the ruminating behavior of calves were observed each day by a person, based on the records, to determine the appearance of first rumination of calves. Once the first rumination was observed, the observation of that particular calf was stopped. Based on the observation of these 6 calves, we found that the first ruminating behavior mainly included 4 parts, as follows: (1) calf curled up with head lying on bedding (lying behavior: lying on the sternum with head held in a raised position or down); (2) calf licked the hair of its belly (this process lasts 30-40 s); (3) after 20 to $30 \mathrm{~s}$, calf begins to retch, which lasted 1 to 2 min (retching: the left abdomen of the calf shows visible downward and upward movements, and when the left abdomen shows downward movement, the calf stretches its neck forward with the opened mouth; inversely, the calf returns to the normal-lying state when the left abdomen shows the upward movement); (4) the calf begins to chew regularly, which lasted 2 to $3 \mathrm{~min}$. This is the first regular chewing behavior observed in calves without intake of solid feed after birth; therefore, we define this as the first ruminating behavior of calves.

\section{Formal Experiment}

A total of 56 healthy, newborn Holstein Friesian calves (40.1 $\pm 3.95 \mathrm{~kg}$; male:female $=1: 2$; belonging to 3 sires) were selected for the formal experiment. After birth, the calves were removed from the delivery room, the ear was tagged, the umbilical cord was disinfected, and calves were fed colostrum in a transit house. After staying in the transit house for $1 \mathrm{~d}$, the calves were reared individually in $1.5 \times 3 \times 1.2-\mathrm{m}^{3}$ calf pens equipped with infrared cameras from $2 \mathrm{~d}$ of age. Bedding for the calves was straw. Each calf consumed a total of $6 \mathrm{~L}$ of colostrum, with $4 \mathrm{~L}$ fed within $2 \mathrm{~h}$ of

Table 1. Descriptions of recorded calf behaviors

\begin{tabular}{ll}
\hline Behavior & Description \\
\hline Ruminating & Regular chewing movement (head up; ears toward the back of most calves) without intake of any feed \\
Eating bedding & $\begin{array}{l}\text { Mouth of calf is obviously close to or deep into the bedding with the jaw moving; then the head rises to } \\
\text { produce chewing }\end{array}$ \\
Non-nutritional oral behavior & $\begin{array}{l}\text { The mouth of calf is close to the surface of the objects (itself, railing, bucket, wall) with obvious tongue } \\
\text { licking; does not produce chewing after licking }\end{array}$ \\
Standing & Standing, walking, or running upright \\
\hline
\end{tabular}




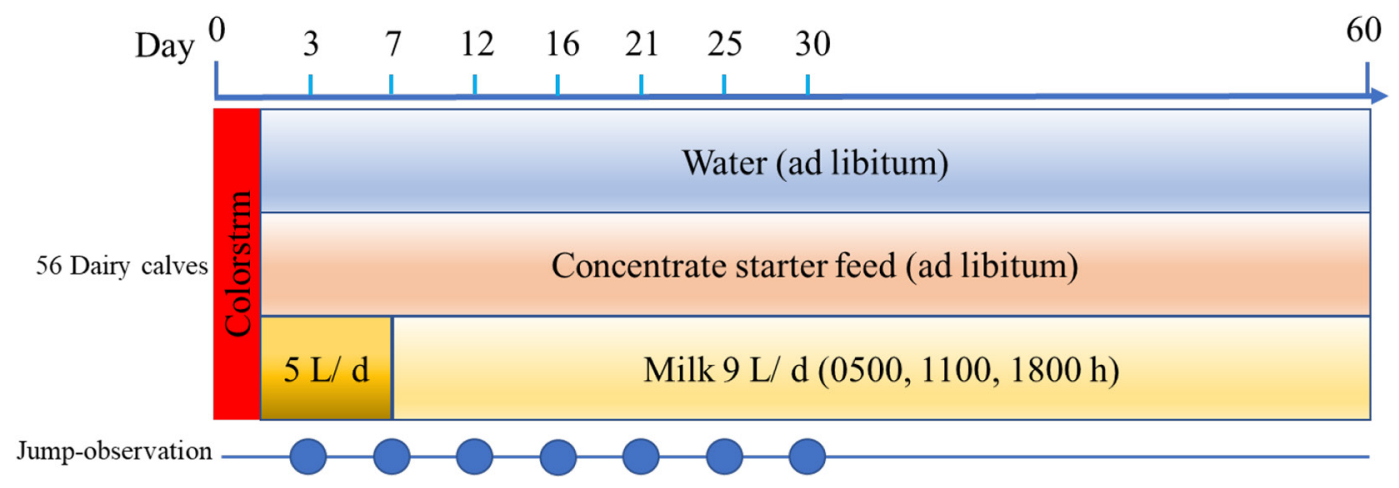

Figure 2. Scheme for collecting dietary and behavioral data from calves $(\mathrm{n}=56)$. Jump-observation is a method of observing behavior.

life and the remaining $2 \mathrm{~L}$ fed $8 \mathrm{~h}$ after the first feeding. The calves were offered $5 \mathrm{~L}$ of pasteurized milk per day from 2 to $7 \mathrm{~d}$ of age, and $9 \mathrm{~L}$ of pasteurized milk with their 3 meals every day (at 0600, 1200, and $1900 \mathrm{~h}$ ) from 8 to $60 \mathrm{~d}$ of age. At $61 \mathrm{~d}$ of age, the calves started weaning, and the experiment was ended. During the experiment, the calves were fed commercial and pelleted concentrate starter feed (Lian Ying Co. Ltd.; water content: $11.34 \%$, crude protein: $20.31 \%$, crude ash: $7.11 \%$, crude fiber: $8.45 \%$, calcium: $1.10 \%$, and phosphorus: $0.62 \%$ ) ad libitum from $3 \mathrm{~d}$ of age, and they had free access to clean, fresh drinking water. The pens were cleaned and the straw changed before $0600 \mathrm{~h}$ every day, to ensure the health and hygiene of the calves. An experienced veterinarian supervised all calves daily. According to the feeding records of the veterinarian and the breeding records of the dairy farm, we collected data on the parity of dams (Table 2) and the number of occurrences of diarrhea from birth to $30 \mathrm{~d}$ of age (TD30) for all calves. Meanwhile, the calves were weighed at birth (IBW) and at $61 \mathrm{~d}$ of age (BW61), before the morning feeding. The starter feed was changed at $0800 \mathrm{~h}$ each day, and the amount of

Table 2. Records of sire and parity of dams for all calves $(\mathrm{n}=56)$

\begin{tabular}{lcc}
\hline Item & Number of calves & Proportion \\
\hline Sire & 23 & 0.41 \\
1 & 12 & 0.21 \\
2 & 21 & 0.38 \\
3 & 56 & 1 \\
Total & & 0.29 \\
Parity of dams & 16 & 0.32 \\
1 & 18 & 0.23 \\
2 & 13 & 0.16 \\
3 & 9 & 1 \\
4 & 56 & \\
Total & \multicolumn{2}{c}{$2.268(1.053)$} \\
Mean (SD) parity & \multicolumn{2}{c}{} \\
\hline
\end{tabular}

starter added and left was recorded to calculate daily intake.

The 56 dairy calves were monitored continuously for $27 \mathrm{~d}$ from $3 \mathrm{~d}$ of age, and all video records were stored in 5 hard disks (Seagate, ST6000VX0023; 6T, 7,200 RPM, 256 MB cache) for behavioral data collection by a person (the same person as in the pre-experiment). To determine the AFR and age of first eating the bedding in calves, we used a jump-observation method, wherein behavioral observations were carried out on 3, $7,12,16,21,25$, and $30 \mathrm{~d}$ of age (each age point was observed continuously from 0000 to $2400 \mathrm{~h}$ ). Then, the minimum age identified at which calves began to ruminate (or eat the bedding) was selected to observe the calves daily until there was no more rumination (or eat the bedding). The data on other behaviors, including standing and ruminating behavior on $3,7,12,16,21$, 25 , and $30 \mathrm{~d}$ of age, non-nutritional oral behavior at 25 and $30 \mathrm{~d}$ of age (NNOB25/30), and duration of eating the bedding at 25 and $30 \mathrm{~d}$ of age (DEB25/30), were collected (Table 1). The diet and the behavioral data collection scheme for the calves $(\mathrm{n}=56)$ is shown in Figure 2.

\section{Environmental Variables}

Calf pens were placed in an open cowshed. In the middle of the cowshed, an automatic temperature and humidity recorder (Maisi Co. Ltd., TH21R) was hung up at hutch height to record the temperature and humidity once every hour (Figure 3 ).

\section{Statistical Analyses}

Statistical analyses were conducted using GraphPad Prism version 8 (GraphPad Software Inc.) and R software version 4.0.3. The statistical power for the samples size of behavior variables this study was $>0.8$ under 
a significance level of 0.05 using $G^{*}$ Power software (version 3.1.9.6, https://g-power.apponic.com). Durations of all behaviors are expressed in minutes. The skim () function in the skimr package (https://CRAN .R-project.org/package=skimr) of $\mathrm{R}$ software is used for descriptive statistics of data. Data were checked for normality using the shapiro.test () function of $\mathrm{R}$ before analyses. Data fitting non-normality were logtransformed (TD30 was square-root transformed). The difference in AFR between male and females was tested using the unpaired $t$-test method in GraphPad. Linear regression analysis between ruminating and standing duration was used in $\mathrm{R}$ as follows: summary (lm (Duration of standing $\sim$ Duration of rumination, data $=$ 'my data of standing and rumination')). The relevant linear model used was as follows:

$$
Y_{i j k}=\mu+\beta X_{i j}+e_{i j k},
$$

where $Y_{i j k}$ is the duration of standing behavior; $\mu$ is the regression constant; $\beta$ is the regression coefficient; $X_{i j}$ is the duration of rumination, where $i$ is the $i$ th calf ( $i$ $=1,2,3, \ldots, 55$, and 56) and $j$ is the $j$ th day's age of observation $(j=3,7,12,16,21,25$, and $30 \mathrm{~d}$ of age); and $e_{i j k}$ is the error term.

To explore the influence of the first rumination on the apparent indicators, we divided AFR into 3 periods (11-15, 16-20, and 21-25 d of age) and analyzed behavioral indicators, including NNOB, duration of eating bedding, rumination, and standing behavior, by ANCOVA in R as follows: summary (aov (behavioral indicator $\sim \mathrm{IBW}+$ temperatures at 25 or $30 \mathrm{~d}$ of age + humidity at 25 or $30 \mathrm{~d}$ of age + AFR, data $=$ 'my data of behavioral indicators')). For example, analyzing NNOB25 will add the effects of the temperature at $25 \mathrm{~d}$ of age and humidity at $25 \mathrm{~d}$ of age. Among them, "my data of behavioral indicators" refers to the file containing all the behavioral indicators data, and "behavioral indicator" refers to the specific indicator to be analyzed in "my data of behavioral indicators," such as NNOB25/30 and DEB25/30. The relevant linear model used was as follows:

$Y_{i j k}=\mu+A F R_{i}+\alpha\left(R_{j}-\bar{R}\right)+\beta\left(S_{j}-\bar{S}\right)+\gamma\left(T_{j}-\bar{T}\right)+e_{i j k}$,

where $Y_{i j k}$ is the dependent variable; $\mu$ is the average experimental value; $A F R_{i}$ is the fixed effect of period $i$ ( $i=11-15 \mathrm{~d}, 16-20 \mathrm{~d}$, or $21-25 \mathrm{~d}$ of age); $\alpha\left(R_{j}-\bar{R}\right)$ designates the covariate variable of IBW, where $\alpha$ is the regression coefficient relating IBW to the variable measured, $R_{j}$ is the IBW for the $j$ th calf $(j=1,2,3, \ldots$ . , 55, and 56), and $\bar{R}$ is the overall mean of the IBW; $\beta\left(S_{j}-\bar{S}\right)$ designates the covariate variable of air temperature, where $\beta$ is the regression coefficient relating air temperature to the variable measured, $S_{i}$ is the air temperature at 25 or $30 \mathrm{~d}$ of age for the $j$ th calf, and $\bar{S}$

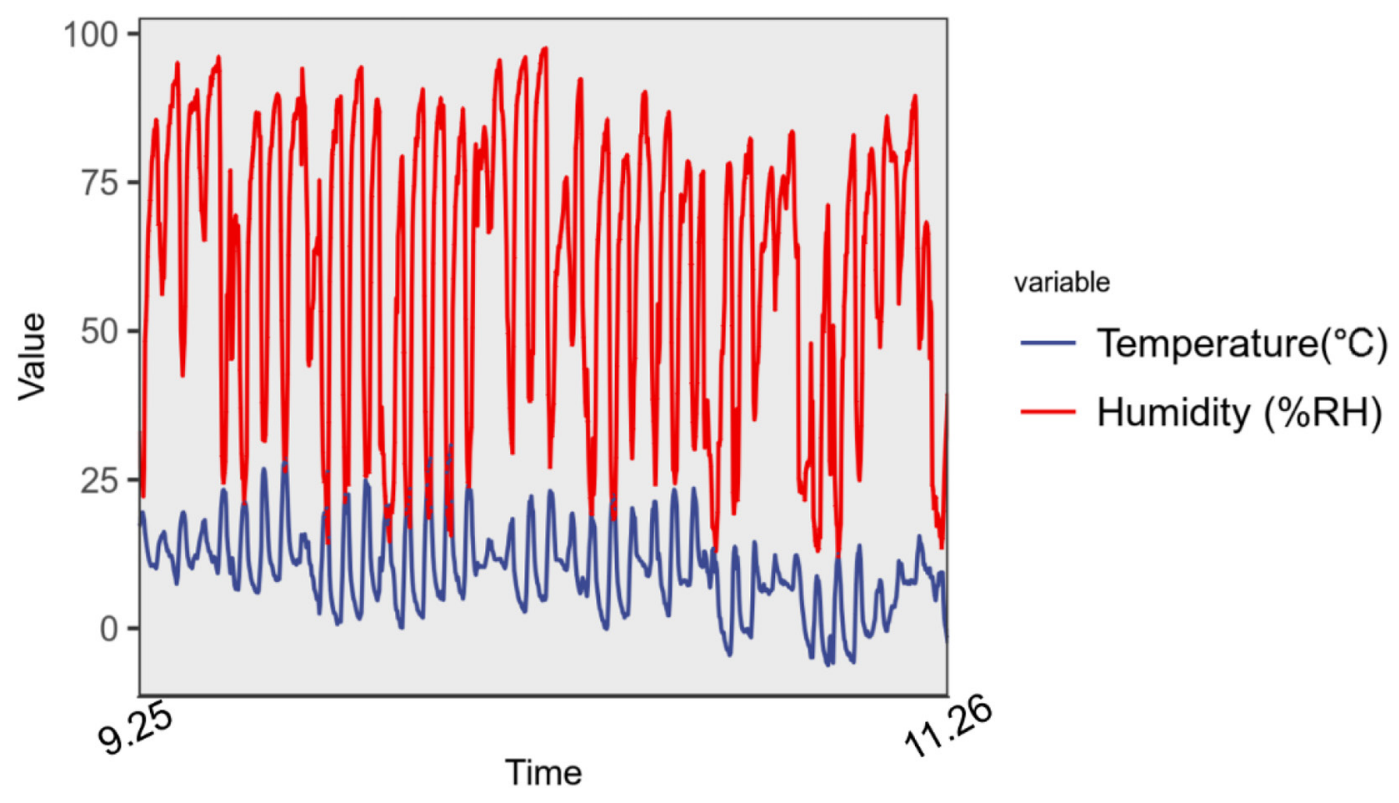

Figure 3. Changes in temperature and humidity (relative humidity, RH) during the experiment. $9.25=$ September 25,$2019 ; 11.26=$ November 26, 2019. 
Table 3. Verification of first ruminating behavior pattern (number of calves in each time interval) in the preliminary experiment

\begin{tabular}{|c|c|c|c|c|c|c|c|c|}
\hline Parts of first rumination & \multicolumn{8}{|c|}{ Time interval } \\
\hline Calf curled up with head on the straw & - & - & - & - & - & - & - & - \\
\hline Calf began to retch & - & - & - & - & 16 & 28 & 9 & 3 \\
\hline Calf began to chew regularly & - & - & - & - & 19 & 11 & 25 & 1 \\
\hline
\end{tabular}

is the overall mean of the air temperature at 25 or $30 \mathrm{~d}$ of age for calves; $\gamma\left(T_{j}-\bar{T}\right)$ designates the covariate variable of air humidity, where $\gamma$ is the regression coefficient relating air humidity to the variable measured, $T_{j}$ is the air humidity at 25 or $30 \mathrm{~d}$ of age for the $j$ th calf, and $\bar{T}$ is the overall mean of the air humidity at 25 or $30 \mathrm{~d}$ of age for the calves; and $e_{i j k}$ is the error term.

When analyzing the other apparent indicators, including body weight, feed intake, and the number of occurrences of diarrhea, we use another ANCOVA in R as follows: summary (aov (Apparent indicator $\sim \mathrm{IBW}$ $+\mathrm{AFR}$, data $=$ "my data of apparent indicators')). Similarly, "my data of apparent indicators" refers to the file containing all the other apparent indicators data, and "Apparent indicator" refers to the specific indicator to be analyzed in "my data of apparent indicators," such as BW61, TD30, or average daily starter feed intake within $30 \mathrm{~d}$ of age (ADFI30). The relevant linear model used was as follows:

$$
Y_{i j k}=\mu+A F R_{i}+\alpha\left(X_{j}-\bar{X}\right)+e_{i j k}
$$

where $Y_{i j k}$ is the dependent variable; $\mu$ is the average experimental value; $A F R_{i}$ is the fixed effect of period $i$ $(i=11-15,16-20$, or $21-25 \mathrm{~d}$ of age $) ; \alpha\left(X_{j}-\bar{X}\right)$ designates the covariate variable of IBW, where $\alpha$ is the regression coefficient relating IBW to the variable measured, $X_{j}$ is the IBW for the $j$ th calf $(j=1,2,3, \ldots$, 55 , and 56), and $\bar{X}$ is the overall mean of the IBW; and $e_{i j k}$ is the error term.

If there was a coeffect in the process of analyzing, we used the effects () function in the effects package (https://CRAN.R-project.org/web/packages/effects/) to remove covariate factors and to correct the average value of apparent indicators as follows: effects ("AFR", aov (Behavioral indicator $\sim$ IBW + temperatures at 25 or $30 \mathrm{~d}$ of age + humidity at 25 or $30 \mathrm{~d}$ of age $+\mathrm{AFR}$, data $=$ "my data of behavioral indicators")) or effects ("AFR", aov (Apparent indicator IBW + $\mathrm{AFR}$, data $=$ "my data of apparent indicators")). Next, mean for period effect was separated using a Tukey adjustment (TukeyHSD () function in R software) when the overall F-test was $P<0.05$. The ggcor package github (houyunhuang/ggcor) of $\mathrm{R}$ was used to analyze the relationship between AFR and apparent and behavioral indicators (based on Pearson's coefficient). All data were reported as means. Differences of $P<0.05$ were considered significant, and $0.05 \leq P \leq 0.10$ were considered to show a tendency of difference.

\section{RESULTS}

\section{Distribution of Age of First Ruminating Behavior}

First, we verified the description of first rumination in the pre-experiment and counted the number of calves for the duration of each part of first rumination (except the first part; Table 3). The results showed that the first rumination of calves basically followed the pattern observed in the pre-experiment. We found that AFR fitted normal distribution: the earliest AFR was recorded at $9 \mathrm{~d}$ of age and the latest at $28 \mathrm{~d}$ of age, and in $50 \%$, or a majority, of the calves, the AFR was 15 to $20 \mathrm{~d}$ of age (Figure 4). Furthermore, Table 4 shows that the range and standard deviation (SD) of AFR were 19 $\mathrm{d}$ and 4.523, respectively, indicating that the individual difference was relatively large, but no significant difference was found in the AFR between male and female calves $(18.05 \pm 4.453 \mathrm{~d}$ vs. $16.79 \pm 4.662 \mathrm{~d} ; P=0.326)$.

\section{Development of Ruminating and Standing Behavior}

We found that the duration of standing behavior in the calves from birth to $30 \mathrm{~d}$ of age first showed a rising trend, then decreased, and subsequently became stable by the end of the observation period (Figure $5)$. The ruminating duration in the calves increased with age during the observation period (Figure 5). We divided the observation period into 2 periods of 3 to 16 $\mathrm{d}$ and 16 to $30 \mathrm{~d}$ of age, to further explore the relationship between rumination and standing behavior using regression analysis. We found little correlation in the period of 3 to $16 \mathrm{~d}$ of age $\left(\mathrm{R}^{2}=0.07 ; P=0.001\right)$ as 


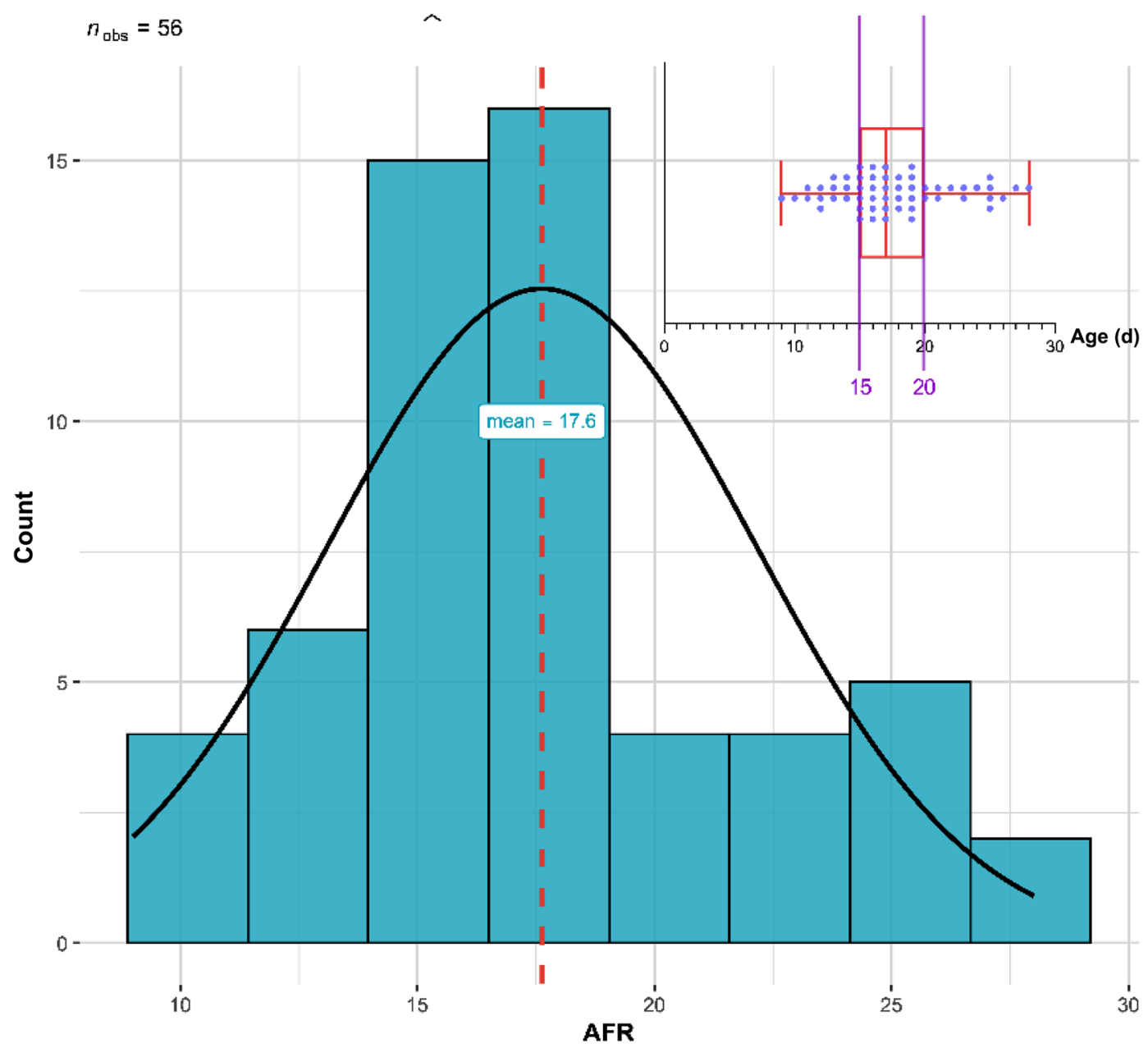

Figure 4. Age distribution of calves' first rumination. AFR = age at first rumination; $n_{\mathrm{obs}}=$ number of observations.

well as from 16 to $30 \mathrm{~d}$ of age $\left(\mathrm{R}^{2}=0.09 ; P=0.001\right.$; Figure 6).

\section{Other Apparent Indicators}

The results of the descriptive statistical analyses of the other calf indicators are shown in Table 5 . We found large differences between the individual calves, with ranges and SD as follows: age of first eating the bedding, $10 \mathrm{~d}$ and 2.93; duration of first eating the bedding, $30 \mathrm{~min}$ and 6.58; total intake of starter feed before first rumination, $1,870 \mathrm{~g}$ and 393.9 ; duration of NNOB25 or $30,48 \mathrm{~min}$ or $39 \mathrm{~min}$ and 10 or 10.7 ; DEB25 or 30, 83 min or $94 \mathrm{~min}$ and 18.49 or 24.09; TD30, 6 bouts and 1.27; IBW, $16 \mathrm{~kg}$ and 3.95; BW61, $22 \mathrm{~kg}$ and 5.09; total starter feed intake within $30 \mathrm{~d}$ of age, 4,185 $\mathrm{g}$ and 991.2; and ADFI30, $155 \mathrm{~g}$ and 36.71. However, the results showed that, although the mean duration of first eating the bedding was short (13.36 \pm $6.58 \mathrm{~min})$, calves began eating bedding at an early age $(6.4 \pm 2.93 \mathrm{~d})$, and 4 calves $(7.1 \%)$ had not begun to eat starter feed before their first rumination. The mean BW61 $(84.1 \pm 5.09 \mathrm{~kg})$ was twice the mean IBW $(40.1$ $\pm 3.95 \mathrm{~kg}$ ), and the mean ADG was $0.7 \mathrm{~kg}$ (Table 5$)$.

Table 4. Descriptive statistics for the age of first ruminating behavior in the calves

\begin{tabular}{lcccccccc}
\hline Calves & Number & Minimum & Median & Maximum & Mean & Max - Min & SD & $P$-value \\
\hline Male & 37 & 10 & 17 & 28 & 18.05 & 18 & 4.453 \\
Female & 19 & 9 & 16 & 27 & 16.79 & 18 & 4.662 \\
All & 56 & 9 & 17 & 28 & 17.63 & 19 & 4.523 \\
\hline
\end{tabular}




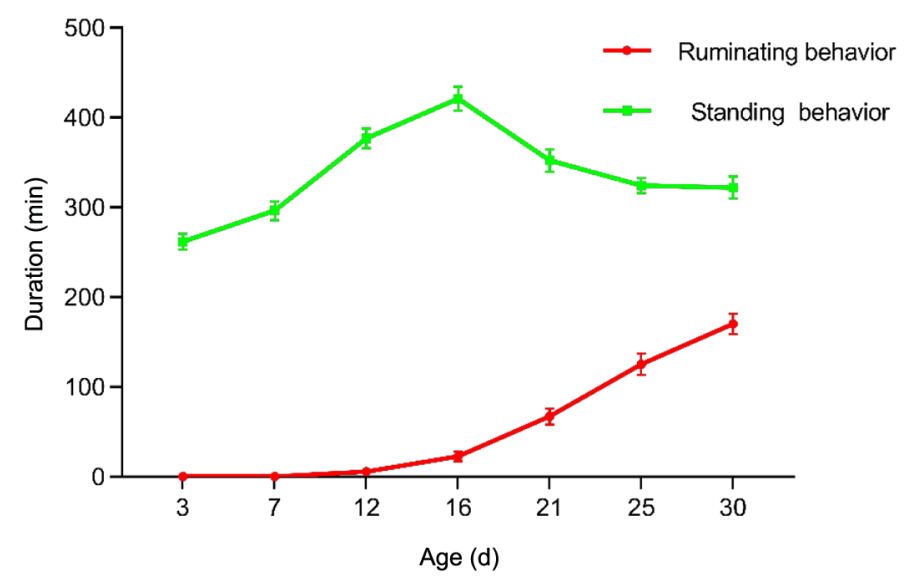

Figure 5. Trends in rumination and standing behavior from birth to $30 \mathrm{~d}$ of age (mean $\pm \mathrm{SEM}$ ).

\section{Relationship Between AFR and Other Apparent Indicators}

To further explore the relationship between AFR and other apparent indicators, we grouped the calves according to their different AFR and found that the duration of ruminating behavior at 25 and $30 \mathrm{~d}$ of age, and DEB25 in the 11 to $15 \mathrm{~d}$ of age group, were higher than in the 21 to $25 \mathrm{~d}$ of age group (157.4 vs. $60.3 \mathrm{~min}$ and 214.6 vs. $117.9 \mathrm{~min}, \mathrm{SEM}=16.82$ and $17.71, P=$ 0.001 and $0.006 ; 42.2$ vs. $24.8 \mathrm{~min}, \mathrm{SEM}=4.16, P=$ 0.007; Table 6); NNOB30 in the 11 to $15 \mathrm{~d}$ and 16 to 20 $\mathrm{d}$ of age groups were lower than the 21 to $25 \mathrm{~d}$ of age group (28.2 and 29.1 vs. $38.0 \mathrm{~min}, \mathrm{SEM}=2.50, P=$ 0.040; Table 6). Meanwhile, the duration of NNOB25, DEB30, duration of standing behavior at $25 \mathrm{~d}$ of age, BW61, ADG, total starter feed intake within $30 \mathrm{~d}$ of age, and ADFI30 showed a tendency of difference by the period of AFR (30.4 vs. 32.6 vs. $37.9 \mathrm{~min}, \mathrm{SEM}=$ $2.19, P=0.081 ; 50.8$ vs. 46.4 vs. $33.9 \mathrm{~min}, \mathrm{SEM}=5.46$, $P=0.051 ; 308.4$ vs. 328.5 vs. $346.1 \mathrm{~min}, \mathrm{SEM}=8.41$, $P=0.077 ; 84.6$ vs. 83.8 vs. $82.8 \mathrm{~kg}, \mathrm{SEM}=1.27, P=$ $0.064 ; 0.8$ vs. 0.7 vs. $0.7 \mathrm{~kg}, \mathrm{SEM}=0.73, P=0.058$; $2,204.0$ vs. $1,711.0$ vs. $1,308.0$ g, $\mathrm{SEM}=228.53, P=$ $0.054 ; 81.6$ vs. 63.4 vs. $48.4 \mathrm{~g}, \mathrm{SEM}=8.47, P=0.054$; Table 6).

The correlation coefficient of each indicator was analyzed using $\mathrm{R}$ software. The total starter feed intake within $30 \mathrm{~d}$ of age, ADFI30, duration of ruminating behavior at 25 and $30 \mathrm{~d}$ of age, duration of rumination at $30 \mathrm{~d}$ of age, DEB25, and DEB30 were negatively correlated with AFR $(\mathrm{r}=-0.36,-0.36,-0.68$, $-0.56,-0.37$, and -0.37 , respectively; $P<0.05$; Figure 7b). However, we found positive correlations between NNOB30, duration of standing behavior at $25 \mathrm{~d}$ of age,

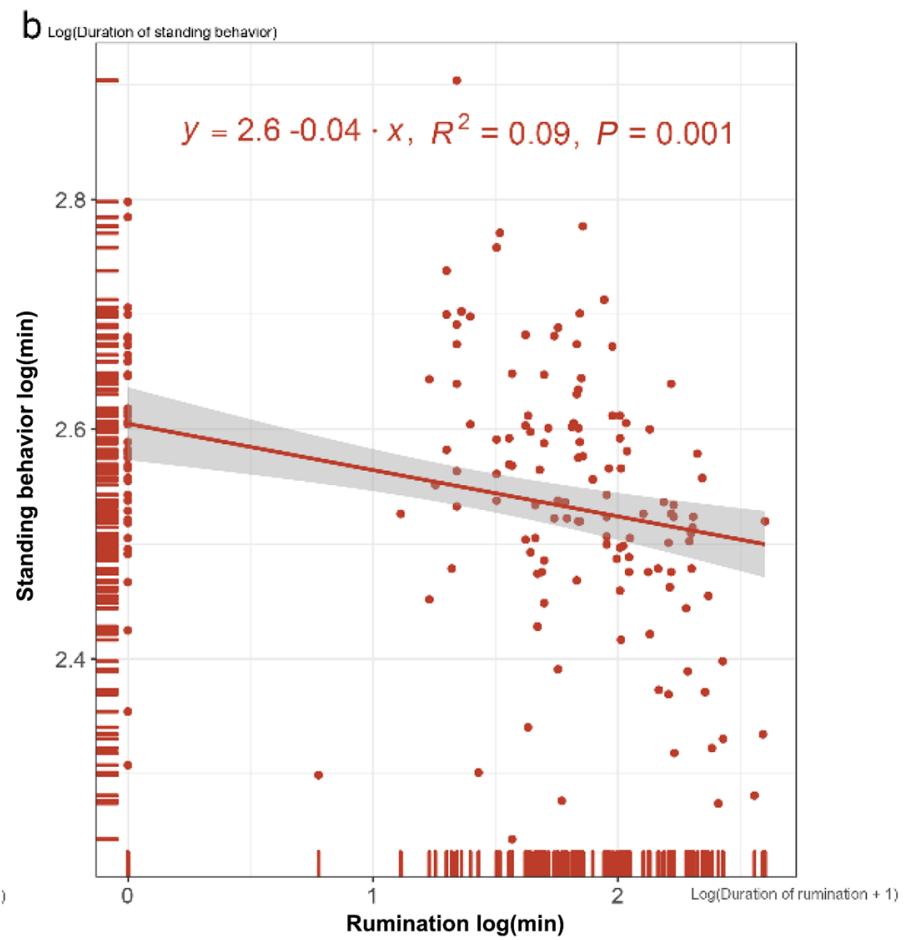

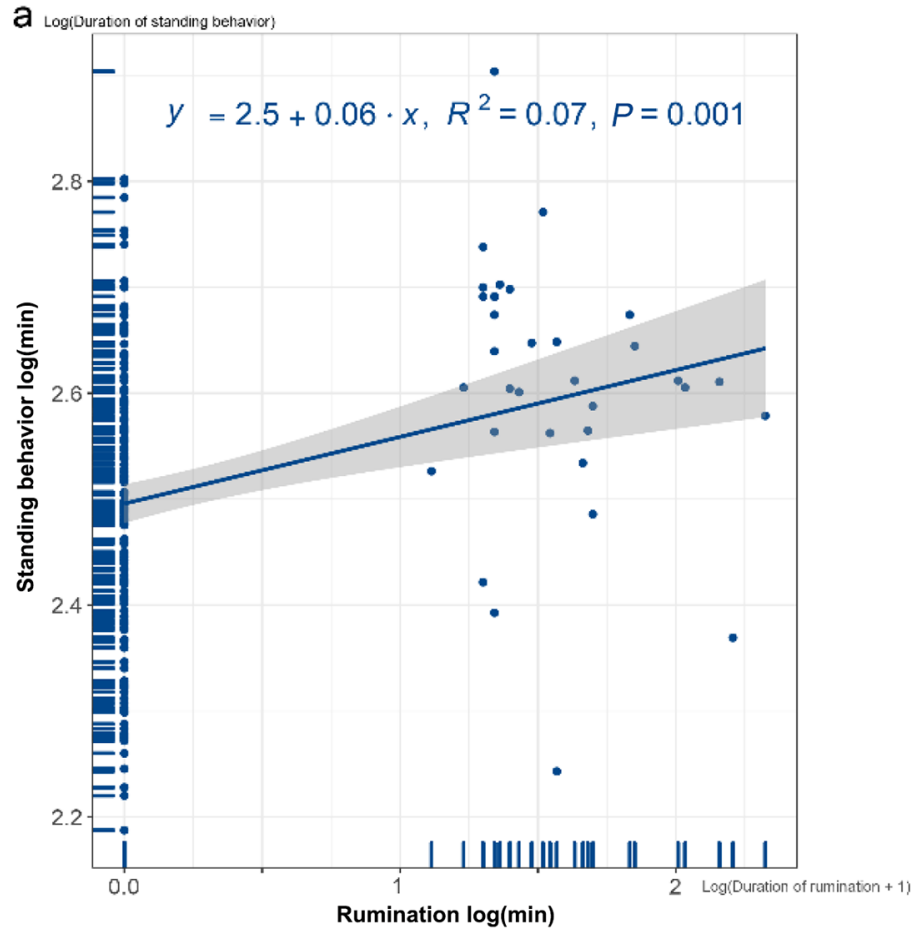

Figure 6. Regression analysis of rumination and standing behavior. Regression analysis of rumination and standing behavior between (a) d 3 and 16 , and (b) d 16 and 30. 
Wang et al.: RUMINATING BEHAVIOR IN HOLSTEIN CALVES

Table 5. Descriptive statistics for apparent indicators in the calves $(\mathrm{n}=56)$

\begin{tabular}{lcccccc}
\hline Item $^{1}$ & Minimum & Median & Maximum & Mean & Max - Min & SD \\
\hline NNOB (min) & 13 & 33.5 & 61 & 32.6 & 48 & 10 \\
d 25 & 12 & 30 & 51 & 30.2 & 39 & 10.7 \\
d 30 & & & & & & \\
DEB (min) & 7 & 33 & 90 & 35.2 & 83 & 18.49 \\
d 25 & 14 & 40 & 108 & 44.5 & 94 & 24.09 \\
d 30 & 0 & 2 & 6 & 2.2 & 6 & 1.27 \\
TD30 (bouts) & 105 & 1,652 & 4,290 & 1,768 & 4,185 & 991.2 \\
TFI30 (g) & 3.9 & 61.2 & 158.9 & 65.5 & 155 & 36.71 \\
ADFI30(g) & 31 & 41 & 47 & 40.1 & 16 & 3.95 \\
IBW (kg) & 70 & 85 & 92 & 84.1 & 22 & 5.09 \\
BW61 (kg) & 0.6 & 0.7 & 0.8 & 0.7 & 0.2 & 0.14 \\
ADG (kg/d) & 3 & 6 & 13 & 6.4 & 10 & 2.93 \\
AFE (d) & 2 & 13.5 & 32 & 13.36 & 30 & 6.58 \\
DFE (min) & 0 & 305 & 1,870 & 402.3 & 1,870 & 393.9 \\
TIR (g) & & & & & & \\
\hline
\end{tabular}

${ }^{1} \mathrm{NNOB}=$ duration of non-nutritive oral behavior; $\mathrm{DEB}=$ duration of eating the bedding; TD30 = number of occurrences of diarrhea within $30 \mathrm{~d}$ of age; TFI30 = total starter feed intake within $30 \mathrm{~d}$ of age; ADFI30 = average daily starter feed intake within $30 \mathrm{~d}$ of age; IBW = initial body weight; BW61 = body weight at 61 $\mathrm{d}$ of age; $\mathrm{AFE}=$ age of first eating bedding; $\mathrm{DFE}=$ duration of eating the bedding at AFE; and TIR = total intake of starter feed before the first rumination.

and AFR $(\mathrm{r}=0.33,0.31 ; P<0.05 ;$ Figure $7 \mathrm{a})$. We also explored what may affect AFR in calves. Interestingly, AFR was positively correlated with age of first eating the bedding $(\mathrm{r}=0.55 ; P<0.05)$ and total intake of starter feed before first rumination $(\mathrm{r}=0.37 ; P<0.05$; Figure 7a).

\section{DISCUSSION}

In this study, we observed calf behavior (with sufficient sample size) through strict behavioral definitions under feeding management wherein calves were fed only pelleted starter feed and milk. Under the same feeding management and during the preweaning period, the ADG of calves was $0.69 \mathrm{~kg} / \mathrm{d}$ according to Zhang et al. (2019), $0.61 \mathrm{~kg} / \mathrm{d}$ according to Qadeer et al. (2021), $0.65 \mathrm{~kg} / \mathrm{d}$ according to Mohtashami et al. (2021), and $0.7 \mathrm{~kg} / \mathrm{d}$ in our study, which indicated that the data obtained in this study were of good reference value.

Ruminating behavior has been studied extensively in dairy cows, as it is correlated with their production performance and health status, and is a good indicator by which to monitor their health (Kaufman et al., 2016; Abeni and Galli, 2017; Johnston and DeVries,

Table 6. Apparent indicators of calves when grouped according to ages of their first ruminating behaviors

\begin{tabular}{|c|c|c|c|c|c|}
\hline \multirow[b]{2}{*}{ Item $^{1}$} & \multicolumn{3}{|c|}{ Period for first rumination (d) } & \multirow[b]{2}{*}{ SEM } & \multirow[b]{2}{*}{$P$-value } \\
\hline & $11-15$ & $16-20$ & $21-25$ & & \\
\hline $\mathrm{R} 25$ (min) & $157.4^{\mathrm{a}}$ & $133.6^{\mathrm{ab}}$ & $60.3^{\mathrm{b}}$ & 16.82 & $<0.001$ \\
\hline R30 (min) & $214.6^{\mathrm{a}}$ & $162.1^{\mathrm{ab}}$ & $117.9^{\mathrm{b}}$ & 17.71 & 0.006 \\
\hline NNOB25 (min) & 30.4 & 32.6 & 37.9 & 2.19 & 0.081 \\
\hline NNOB30 (min) & $28.2^{\mathrm{b}}$ & $29.1^{\mathrm{b}}$ & $38.0^{\mathrm{a}}$ & 2.50 & 0.040 \\
\hline DEB25 (min) & $42.2^{\mathrm{a}}$ & $36.3^{\mathrm{ab}}$ & $24.8^{\mathrm{b}}$ & 4.16 & 0.007 \\
\hline DEB30 (min) & 50.8 & 46.4 & 33.9 & 5.46 & 0.051 \\
\hline BW61 (kg) & 84.6 & 83.8 & 82.8 & 1.27 & 0.064 \\
\hline $\mathrm{ADG}(\mathrm{kg} / \mathrm{d})$ & 0.8 & 0.7 & 0.7 & 0.73 & 0.058 \\
\hline TFI30 (g) & $2,204.0$ & $1,711.0$ & $1,308.0$ & 228.53 & 0.054 \\
\hline ADFI30 (g/d) & 81.6 & 63.4 & 48.4 & 8.47 & 0.054 \\
\hline TD30 (bouts) & 2.3 & 2.0 & 2.3 & 0.18 & 0.997 \\
\hline $\mathrm{S} 25$ (min) & 308.4 & 328.5 & 346.1 & 8.41 & 0.077 \\
\hline $\mathrm{S} 30(\min )$ & 304.5 & 348 & 324.6 & 12.56 & 0.538 \\
\hline
\end{tabular}

\footnotetext{
$\overline{\mathrm{a}, \mathrm{b}}$ Significantly different $(P<0.05)$ means within the same row of data are indicated by different superscript letters.

${ }^{1} \mathrm{R} 25, \mathrm{R} 30=$ duration of rumination at 25 and $30 \mathrm{~d}$ of age; NNOB25, NNOB30 = duration of non-nutritive oral behavior at 25 and $30 \mathrm{~d}$ of age; DEB25, DEB30 = duration of eating bedding at 25 and $30 \mathrm{~d}$ of age; BW61 $=$ body weight at $61 \mathrm{~d}$ of age; TFI30 = total starter feed intake within $30 \mathrm{~d}$ of age; ADFI30 = average daily starter feed intake within $30 \mathrm{~d}$ of age; TD30 = number of occurrences of diarrhea within $30 \mathrm{~d}$ of age; and S25, $\mathrm{S} 30=$ duration of standing behavior at 25 and $30 \mathrm{~d}$ of age.
} 
2018). However, few studies have been conducted on the ruminating behavior of 1-mo-old calves, because they are often thought of as being in the nonruminant stage, in which calves must be brought into contact with solid feed as early as possible between 0 and $30 \mathrm{~d}$ of age. Solid feed is the basis of ruminal development; therefore, early exposure to solid feed is beneficial to rumen development and microbial colonization of calves, which lays a solid foundation for use of solid

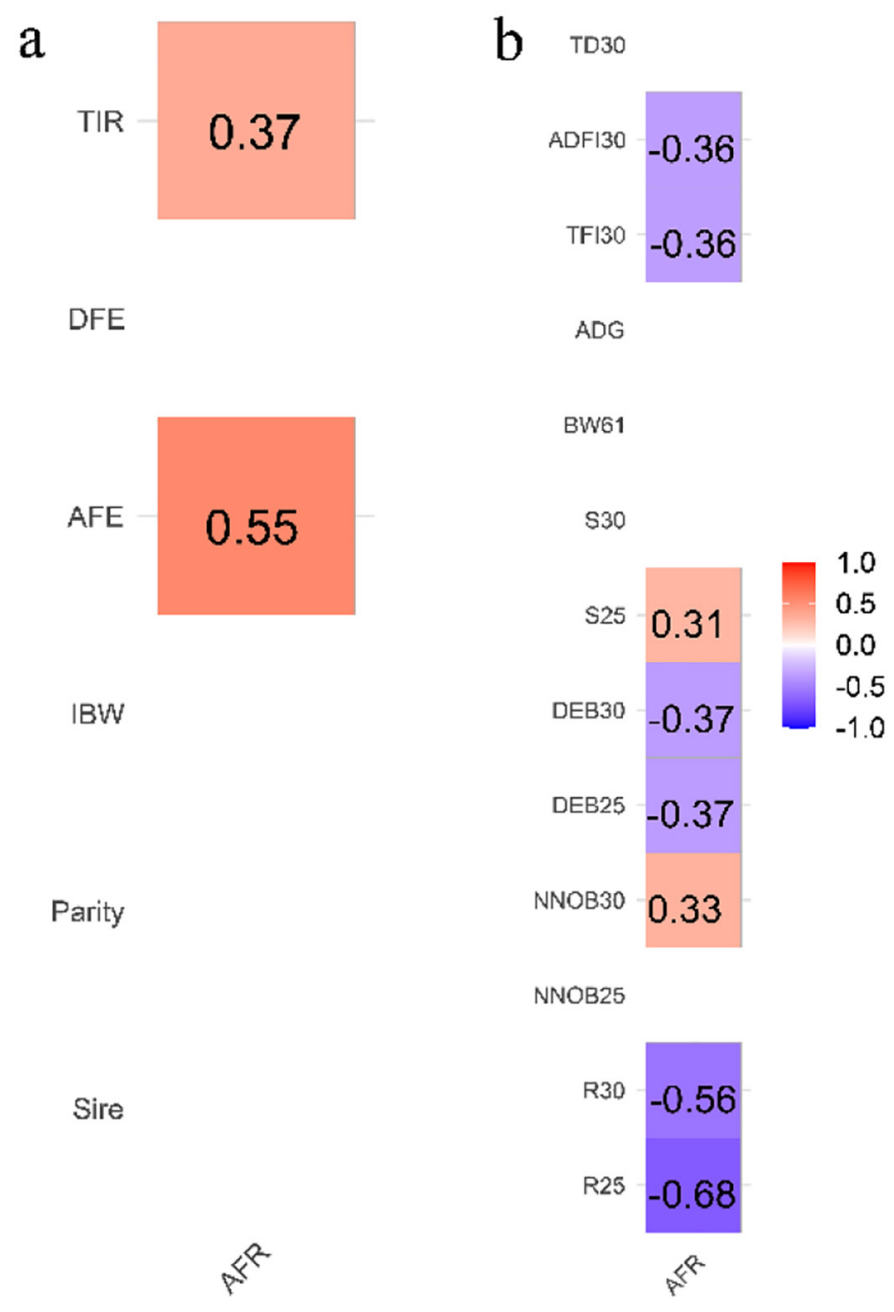

Figure 7. Correlation analysis between age at first rumination (AFR) and other characteristics before AFR (a) and after AFR (b). Red represents a positive correlation, and blue represents a negative correlation. The red-to-blue scale bar running from 1.0 to -1.0 represents correlation coefficient $\mathrm{r}$ from 1.0 to -1.0 . Blank spaces next to characteristics represent $P>0.05$. TIR $=$ total intake of starter feed before first rumination; $\mathrm{AFE}=$ age of first eating the bedding; $\mathrm{DFE}$ $=$ duration of eating bedding at AFE; IBW = initial body weight; S25, S30 = duration of standing behavior at d 25 and 30; TD30 = number of occurrences of diarrhea within d 30; ADFI30 = average daily starter feed intake within d 30; TFI30 $=$ total starter feed intake within d 30; BW61 = body weight at d 61; DEB25, DEB30 = duration of eating the bedding at d 25 and 30; NNOB25, NNOB30 $=$ duration of non-nutritive oral behavior at d 25 and 30; R25, R30 = duration of ruminating behavior at $\mathrm{d} 25$ and 30 . feed after weaning (Khan et al., 2011a; Diao et al., 2019). A study has suggested that the tendency for calves to ruminate may be correlated with the development of the gastrointestinal tract (Swanson and Harris, 1958). Our current results showed that, although AFR is mainly 15 to $20 \mathrm{~d}$ of age in calves, it is also found to be distributed over a wide range, from 9 to $28 \mathrm{~d}$ of age, which may indicate that the gastrointestinal tracts of different calves begin to develop at different times.

With increasing concern for the welfare of dairy cows, standing time is considered to harm the welfare of dairy cows by some studies, as longer lying time correlates with better performance (Tucker et al., 2021). In this study, we found an interesting phenomenon, in that standing behavior duration produced an inflection point around $16 \mathrm{~d}$ of age, and the average age of the first rumination of the calves was $17.6 \mathrm{~d}$ of age, which may indicate that the behavior of calves undergoes a major change before and after the age of first rumination. This is also a research point worth further exploration in the future. Many researchers have found that the ruminating behavior of cows either is not or is positively correlated with standing behavior (Schirmann et al., 2012; Stone et al., 2017). However, during the period from 16 to $30 \mathrm{~d}$ of age, we found a negative correlation between standing behavior and ruminating behavior of calves. As we know that cows usually ruminate when lying at rest, if lying behavior is limited, they will ruminate standing, which may also be caused by improper welfare of cows. For suckling calves, rumination while standing is rarely seen in behavioral observations, which indirectly indicates that rumination behavior of suckling calves can be used as an indicator of their welfare.

To explore the reasons for different ages of first rumination, we analyzed the correlations between age of first rumination with parity of dams, sires, and age of first eating the bedding. Age of first eating bedding and intake of forage before rumination were positively correlated with age of first rumination. In ruminants, rumination behavior is malleable, with low hereditary capacity (about 0.3; Moretti et al., 2018). Thus, we believe that the individual eating patterns of calves may affect rumen development, which also explains why the results of previous studies have different results. For example, Swanson and Harris (1958) fed calves coarsechopped alfalfa-grass-mixed hay, and Porter et al. (2007) fed calves no forage. A previous study suggested that injecting catecholamines into the brains of sheep caused them to ruminate temporarily (Ruckebusch and Bardon, 1984). Therefore, these results may indirectly suggest that ruminating behavior may be a natural reward, and forage may be an important welfare point in calf rearing. It is known that the rumen of calves in 
the early period is not fully developed, and its volume is small. When calves eat more starter feed in the early period, higher satiety leads to lower intake of bedding, which can postpone the age of first rumination.

Finally, to investigate the effects of age of first rumination in this study, we found that earlier age of first rumination was associated with shorter durations of non-nutritive oral behaviors, longer durations of rumination and eating the bedding, and higher feed intake during the suckling period. Previous studies have shown that adding forage to concentrate feed can improve the rumen environment, increase the rumen $\mathrm{pH}$, improve the passage rate of feed in the rumen, and increase the intake of solid feed (Castells et al., 2013). Although adding forage does not affect ADG of calves before they are weaned, it can increase the feed intake of calves after weaning (Hill et al., 2008; Castells et al., 2012; Horvath and Miller-Cushon, 2019). In this study, the calves that started to ruminate earlier had higher feed intakes in the later period, but this was not correlated with BW61 and ADG, which was similar to results obtained in previous studies (Phillips, 2004; Castells et al., 2012). Therefore, we believe that the addition of forage may lead to the difference in ruminating function in calves and can affect later feed intake. At present, adding hay or not to the feed of suckling calves is still a controversial question in the field of dairy science. Many studies have shown that feeding hay to calves has beneficial effects on their feed intake, behavior, and development of rumen volume, and that it does not lead to increased gut fill (Khan et al., 2011b; Castells et al., 2013; Cavallini et al., 2018). However, the development of rumen papillae mainly depends on the stimulation of VFA (Miller-Cushon et al., 2013; Malmuthuge et al., 2019). Concentrate feed can produce large amounts of VFA after fermentation (Davis and Drackley, 1998; Yeoman and White, 2014). A recent study showed that, compared with alfalfa hay, soybean hulls (a non-forage fiber source) have more digestible fiber and can contribute to the transformation of the microbiome and the metabolome of calves, produce plentiful VFA, enhance the proportions of propionate and butyrate, and promote the development of the rumen (Wang et al., 2019). Thus, the intake of concentrate feed and nonforage fiber sources, including more digestible fibers, can be conducive to the development of the rumen. Some scholars believe that feeding hay may affect nutrient digestibility (Porter et al., 2007; Daneshvar et al., 2015; Hill et al., 2019), whereas others do not (Castells et al., 2012; Maktabi et al., 2016; Zhao et al., 2020). It has been observed that newborn calves start to graze slowly and that their behavior patterns are similar to those of cows (Hancock, 1953; Nicol and Sharafeldin, 1975). Interestingly, suckling calves prefer hay when they are exposed to solid feed early on (Phillips, 2004; Castells et al., 2012; Kargar and Kanani, 2019). These results suggest that early intake of hay may be a part of the natural development of feeding behavior in calves. Meanwhile, Malmuthuge et al. (2019) showed that in 1-wk-old calves fed only milk, microbiota that could digest solid feed appeared in the rumen, along with methane-producing archaea. This suggests that feeding suitable hay to calves does not decrease their nutrient digestibility in theory. Similarly, we found that if calves were not fed hay at an early stage, they would begin to eat their bedding at a young age. The low nutritional status and satiety of bedding affects growth of calves. Although the physiological functions of the rumen in newborn calves require further investigation, based on the results observed in this study, we suggest that a certain amount of hay should be added in the dietary management of newborn calves to meet their behavioral and physiological needs and produce a positive effect later. Due to the limited experimental conditions, this study did not further explore the development of ruminating behavior and the long-term effects of AFR in calves. However, AFR was found to have a positive effect on the calves in the results. In the future, we believe that AFR could be used as an important aspect of calf physiology to improve feeding and management practices. The long-term influence of AFR on calves, however, requires further investigation using more data recorded by more advanced equipment than was used in this investigation.

\section{CONCLUSIONS}

In this study we observed the changes in ruminating behavior of calves from birth to d 30 of life, and mainly explored the appearance time and influence of the first rumination. The age of first rumination was usually 15 to $20 \mathrm{~d}$ of age and was positively correlated with the age of calves first eating their bedding. We also found that an earlier age of first rumination was associated with shorter durations of non-nutritive oral behaviors, longer durations of rumination and eating bedding, and higher feed intake by $30 \mathrm{~d}$ of age. However, additional long-term studies on the effects of age of first rumination on calves are required.

\section{ACKNOWLEDGMENTS}

This study was supported by the Earmarked Fund for Beijing Dairy Industry Innovation Consortium of Agriculture Research System (BAIC06), the Agricultural Science and Technology Innovation Program (CAAS-ASTIP-2017-FRI-04, Beijing, China), and the Fundamental Research Funds of the Chinese Academy 
of Agricultural Sciences: Establishment and application of healthy breeding technology systems for replacement cattle (Y2021CG04, Beijing, China). The authors have not stated any conflicts of interest.

\section{REFERENCES}

Abeni, F., and A. Galli. 2017. Monitoring cow activity and rumination time for an early detection of heat stress in dairy cow. Int. J. Biometeorol. 61:417-425. https://doi.org/10.1007/s00484-016-1222-z.

Baldwin, R. L., K. R. Mcleod, J. L. Klotz, and R. N. Heitmann. 2004 Rumen development, intestinal growth and hepatic metabolism in the pre- and postweaning ruminant. J. Dairy Sci. 87:E55-E65. https://doi.org/10.3168/jds.S0022-0302(04)70061-2.

Castells, L., A. Bach, G. Araujo, C. Montoro, and M. Terré. 2012. Effect of different forage sources on performance and feeding behavior of Holstein calves. J. Dairy Sci. 95:286-293. https://doi.org/10 .3168/jds.2011-4405.

Castells, L., A. Bach, A. Aris, and M. Terré. 2013. Effects of forage provision to young calves on rumen fermentation and development of the gastrointestinal tract. J. Dairy Sci. 96:5226-5236. https:// doi.org/10.3168/jds.2012-6419.

Cavallini, D., L. M. E. Mammi, M. Fustini, A. Palmonari, A. J. Heinrichs, and A. Formigoni. 2018. Effects of ad libitum or restricted access to total mixed ration with supplemental long hay on production, intake, and rumination. J. Dairy Sci. 101:10922-10928. https://doi.org/10.3168/jds.2018-14770.

Church, D. C. 1988. The Ruminant Animal: Digestive Physiology and Nutrition. Prentice Hall.

Daneshvar, D., M. Khorvash, E. Ghasemi, A. H. Mahdavi, B. Moshiri, M. Mirzaei, A. Pezeshki, and M. H. Ghaffari. 2015. The effect of restricted milk feeding through conventional or step-down methods with or without forage provision in starter feed on performance of Holstein bull calves. J. Anim. Sci. 93:3979-3989. https:/ /doi.org/10.2527/jas.2014-8863.

Davis, C. L., and J. K. Drackley. 1998. The Development, Nutrition, and Management of the Young Calf. Iowa State University Press.

Diao, Q, R Zhang, and T Fu.. 2019. Review of strategies to promote rumen development in calves. Animals (Basel) 9:490. https://doi .org/10.3390/ani9080490.

Ghassemi Nejad, J., N. Torbatinejad, A. A. Naserian, S. Kumar, J. D. Kim, Y. H. Song, C. S. Ra, and K. I. Sung. 2012. Effects of processing of starter diets on performance, nutrient digestibility, rumen biochemical parameters and body measurements of brown swiss dairy calves. Asian-Australas. J. Anim. Sci. 25:980-987. https://doi.org/10.5713/ajas.2011.11457.

Hancock, J. 1953. Grazing behaviour of cattle. Animal Breeding Abstract 21:1-13.

Heinrichs, A. J., and K. E. Lesmeister. 2005. Rumen development in the dairy calf. Pages 53-65 in Calf and Heifer Rearing: Principles of Rearing the Modern Dairy Heifer from Calf to Calving. 60th University of Nottingham Easter School in Agricultural Science. CABI.

Hill, T., T. Dennis, F. Suárez-Mena, J. Quigley, K. Aragona, and R. Schlotterbeck. 2019. Effects of free-choice hay and straw bedding on digestion of nutrients in 7-week-old Holstein calves. Appl. Anim. Sci. 35:312-317. https://doi.org/10.15232/aas.2019-01855.

Hill, T. M., H. G. Bateman II, J. M. Aldrich, and R. L. Schlotterbeck. 2008. Effects of the amount of chopped hay or cottonseed hulls in a textured calf starter on young calf performance. J. Dairy Sci. 91:2684-2693. https://doi.org/10.3168/jds.2007-0935.

Horvath, K. C., and E. K. Miller-Cushon. 2019. Evaluating effects of providing hay on behavioral development and performance of group-housed dairy calves. J. Dairy Sci. 102:10411-10422. https:/ /doi.org/10.3168/jds.2019-16533.

Johnston, C., and T. J. DeVries. 2018. Short communication: Associations of feeding behavior and milk production in dairy cows. J. Dairy Sci. 101:3367-3373. https://doi.org/10.3168/jds.2017-13743.
Kargar, S., and M. Kanani. 2019. Reconstituted versus dry alfalfa hay in starter feed diets of Holstein dairy calves: Effects on feed intake, feeding and chewing behavior, feed preference, and health criteria. J. Dairy Sci. 102:4061-4071. https://doi.org/10.3168/jds .2018-15189

Kaufman, E. I., S. J. LeBlanc, B. W. McBride, T. F. Duffield, and T. J. DeVries. 2016. Association of rumination time with subclinical ketosis in transition dairy cows. J. Dairy Sci. 99:5604-5618. https: //doi.org/10.3168/jds.2015-10509.

Khan, M. A., A. Bach, D. M. Weary, and M. A. von Keyserlingk. 2016. Invited review: Transitioning from milk to solid feed in dairy heifers. J. Dairy Sci. 99:885-902. https://doi.org/10.3168/jds.2015 $-9975$.

Khan, M. A., D. M. Weary, and M. A. von Keyserlingk. 2011a. Invited review: Effects of milk ration on solid feed intake, weaning, and performance in dairy heifers. J. Dairy Sci. 94:1071-1081. https:// doi.org/10.3168/jds.2010-3733.

Khan, M. A., D. M. Weary, and M. A. von Keyserlingk. 2011b. Hay intake improves performance and rumen development of calves fed higher quantities of milk. J. Dairy Sci. 94:3547-3553. https://doi .org/10.3168/jds.2010-3871.

Liu, S., J. Y. Ma, J. H. Li, G. M. Alugongo, Z. H. Wu, Y. J. Wang, S. L. Li, and Z. J. Cao. 2019. Effects of pair versus individual housing on performance, health, and behavior of dairy calves. Animals (Basel) 10:50. https://doi.org/10.3390/ani10010050.

Maktabi, H., E. Ghasemi, and M. Khorvash. 2016. Effects of substituting grain with forage or nonforage fiber source on growth performance, rumen fermentation, and chewing activity of dairy calves. Anim. Feed Sci. Technol. 221:70-78. https://doi.org/10.1016/j .anifeedsci.2016.08.024.

Malmuthuge, N., G. Liang, and L. L. Guan. 2019. Regulation of rumen development in neonatal ruminants through microbial metagenomes and host transcriptomes. Genome Biol. 20:172. https://doi .org/10.1186/s13059-019-1786-0.

Miller-Cushon, E. K., C. Montoro, A. Bach, and T. J. DeVries. 2013. Effect of early exposure to mixed rations differing in forage particle size on feed sorting of dairy calves. J. Dairy Sci. 96:3257-3264. https://doi.org/10.3168/jds.2012-6415.

Mohtashami, B., H. Khalilvandi-Behroozyar, R. Pirmohammadi, M. Dehghan-Banadaky, M. Kazemi-Bonchenari, E. Dirandeh, and M. H. Ghaffari. 2021. The effect of supplemental bioactive fatty acids on growth performance and immune function of milk-fed Holstein dairy calves during heat stress. Br. J. Nutr. 16:1-14. https://doi .org/10.1017/S0007114521000908.

Montoro, C., E. K. Miller-Cushon, T. J. DeVries, and A. Bach. 2013. Effect of physical form of forage on performance, feeding behavior, and digestibility of Holstein calves. J. Dairy Sci. 96:1117-1124. https://doi.org/10.3168/jds.2012-5731.

Moretti, R., M. P. G. de Rezende, S. Biffani, and R. Bozzi. 2018 Heritability and genetic correlations between rumination time and production traits in Holstein dairy cows during different lactation phases. J. Anim. Bre. Gene. 135:293-299. https://doi.org/10 $.1111 /$ jbg. 12346 .

Nicol, A. M., and M. A. Sharafeldin. 1975. Observations on the behaviour of single-suckled calves from birth to 120 days. Proc. N.Z. Soc. Anim. Prod. 35:221-230.

Phillips, C. J. 2004. The effects of forage provision and group size on the behavior of calves. J. Dairy Sci. 87:1380-1388. https://doi.org/ 10.3168/jds.S0022-0302(04)73287-7.

Porter, J. C., R. G. Warner, and A. F. Kertz. 2007. Effect of fiber level and physical form of starter on growth and development of dairy calves fed no forage. Prof. Anim. Sci. 23:395-400. https://doi.org/ 10.15232/S1080-7446(15)30994-3.

Qadeer, M. K., S. A. Bhatti, H. Nawaz, and M. S. Khan. 2021. Effect of milk or milk replacer offered at varying levels on growth performance of Friesian veal calves. Trop. Anim. Health Prod. 53:290. https://doi.org/10.1007/s11250-021-02666-7.

Ruckebusch, Y., and T. H. Bardon. 1984. Evidence for a central opioid control of rumination. Can. J. Anim. Sci. 64:13-15. https://doi .org/10.4141/cjas84-133. 
Schirmann, K., N. Chapinal, D. M. Weary, W. Heuwieser, and M. A. G. von Keyserlingk. 2012. Rumination and its relationship to feeding and lying behavior in Holstein dairy cows. J. Dairy Sci. 95:3212-3217. https://doi.org/10.3168/jds.2011-4741.

Stone, A. E., B. W. Jones, C. A. Becker, and J. M. Bewley. 2017. Influence of breed, milk yield, and temperature-humidity index on dairy cow lying time, neck activity, reticulorumen temperature, and rumination behavior. J. Dairy Sci. 100:2395-2403. https://doi .org/10.3168/jds.2016-11607.

Swanson, E. W., and J. D. Harris Jr.. 1958. Development of rumination in the young calf. J. Dairy Sci. 41:1768-1776. https://doi.org/ 10.3168/jds.S0022-0302(58)91161-5.

Tucker, C. B., M. B. Jensen, A. M. de Passillé, L. Hänninen, and J. Rushen. 2021. Invited review: Lying time and the welfare of dairy cows. J. Dairy Sci. 104:20-46. https://doi.org/10.3168/jds 2019-18074.

Wang, B., M. P. Ma, Q. Y. Diao, and Y. Tu. 2019. Saponin-induced shifts in the rumen microbiome and metabolome of young cattle. Front. Microbiol. 10:356. https://doi.org/10.3389/fmicb.2019 .00356 .

Yeoman, C. J., and B. A. White. 2014. Gastrointestinal tract microbiota and probiotics in production animals. Annu. Rev. Anim. Bios- ci. 2:469-486. https://doi.org/10.1146/annurev-animal-022513 $-114149$.

Zhang, R., W. B. Zhang, Y. L. Bi, Y. Tu, Y. Beckers, H. C. Du, and Q. Y. Diao. 2019. Early feeding regime of waste milk, milk, and milk replacer for calves has different effects on rumen fermentation and the bacterial community. Animals (Basel) 9:443. https://doi.org/ 10.3390/ani9070443.

Zhao, Y. L., S. M. Yan, K. A. Beauchemin, and W. Z. Yang. 2020. Feeding diets varying in forage proportion and particle length to lactating dairy cows: II. Effects on duodenal flows and intestinal digestibility of amino acids. J. Dairy Sci. 103:4355-4366. https:// doi.org/10.3168/jds.2019-17607.

\section{ORCIDS}

S. Wang ๑ https://orcid.org/0000-0003-0225-0612

F. M. Hu () https://orcid.org/0000-0002-0947-8436

L. S. Jiang @ (๑) https://orcid.org/0000-0001-8487-1484

Y. Tu @ https://orcid.org/0000-0002-4324-6188 